\title{
Assessment and improvement of image homogeneity in black-blood T2-weighted turbo spin-echo CMR
}

\author{
Benjamin Wince ${ }^{1 *}$, Lowie M Van Assche ${ }^{1}$, Han W Kim', Lubna Bhatti ${ }^{1}$, Christoph J Jensen ${ }^{1}$, Elizabeth Jenista ${ }^{1}$, \\ Wolfgang G Rehwald ${ }^{2}$, Deneen Spatz ${ }^{1}$, Yong-Yin Kim', Michele Parker', Raymond J Kim ${ }^{1}$
}

From 15th Annual SCMR Scientific Sessions

Orlando, FL, USA. 2-5 February 2012

\section{Background}

Double inversion recovery (DIR) and triple inversion recovery (TIR) prepared Turbo-Spin-Echo (TSE) are the most commonly used sequences for black-blood T2weighted (T2W) cardiac magnetic resonance. For both, cardiac motion often leads to signal loss and image inhomogeneity, which can affect diagnosis. Signal loss artifacts are thought to be due to misalignment of the black-blood preparation with readout. However, the TSE readout itself is also motion sensitive and could lead to signal loss. We examined image homogeneity in routine Black-Blood T2W-TSE and investigated potential improvement by reducing interecho-spacing of the TSE readout.

\section{Methods}

Ten healthy volunteers underwent T2W-CMR using 3 sequences: (a) Standard DIR-TSE (interecho-spacing = $9.66 \mathrm{~ms}$ ), (b) Standard TIR-TSE (interecho-spacing = $9.66 \mathrm{~ms}$ ) and, (c) a Modified DIR-TSE sequence with low interecho-spacing (interecho-spacing $=3.48 \mathrm{~ms}$ ). Reduction in interecho-spacing was accomplished by increasing bandwidth $>4$-fold and utilizing shorter refocusing pulses. Total readout time was held constant for all three sequences, leading to shorter breath-hold times for the modified sequence. In each volunteer, a midventricular short-axis slice was repeatedly imaged with only the timing of readout in diastole changed by $50 \mathrm{~ms}$ increments (between $60-100 \%$ of the cardiac cycle). All images were acquired using coil normalization, slice thickness $=7 \mathrm{~mm}$, and effective echo-time $=60 \mathrm{~ms}$.

${ }^{1}$ Cardiology, Duke University, Durham, NC, USA

Full list of author information is available at the end of the article
Epicardial and endocardial contours were planimetered. Mean image intensity and standard deviation (SD) were measured for the slice. Image homogeneity was defined as the ratio of $\mathrm{SD} /$ mean image intensities x100 (higher values indicate worse homogeneity). The sensitivity of each sequence to readout timing was determined by the maximum change in image homogeneity across the different timepoints of diastole.

\section{Results}

Overall, mean image homogeneity was best for Modified DIR-TSE $(16.1 \pm 7.9)$, compared with Standard DIR-TSE $(23.5 \pm 11.3)$ and Standard TIR-TSE $(27.1 \pm 13.9$, both $\mathrm{p}<0.03)$. Modified DIR-TSE was also less sensitive to readout timing, as the maximum change in image homogeneity across diastole was smaller at $14.4 \pm 9.5$ versus $23.2 \pm 15.9$ and $33.6 \pm 11.1$ for Standard DIR-TSE and TIR-TSE, respectively ( $<<0.05$ for both comparisons). Figure 1 shows representative images demonstrating improved image homogeneity for the Modified DIR-TSE sequence as well as showing less sensitivity to changes in the timing of readout.

\section{Conclusions}

T2-weighted-CMR with Standard-DIR and TIR-TSE is limited by image inhomogeneity and is sensitive to small changes in readout timing. A Modified DIR-TSE with reduced interecho-spacing of readout significantly improves image homogeneity and robustness to variation in readout timing. This may reduce the risk of misdiagnosis.

\section{Funding}

Funded in part by 5R01HL064726-07. 


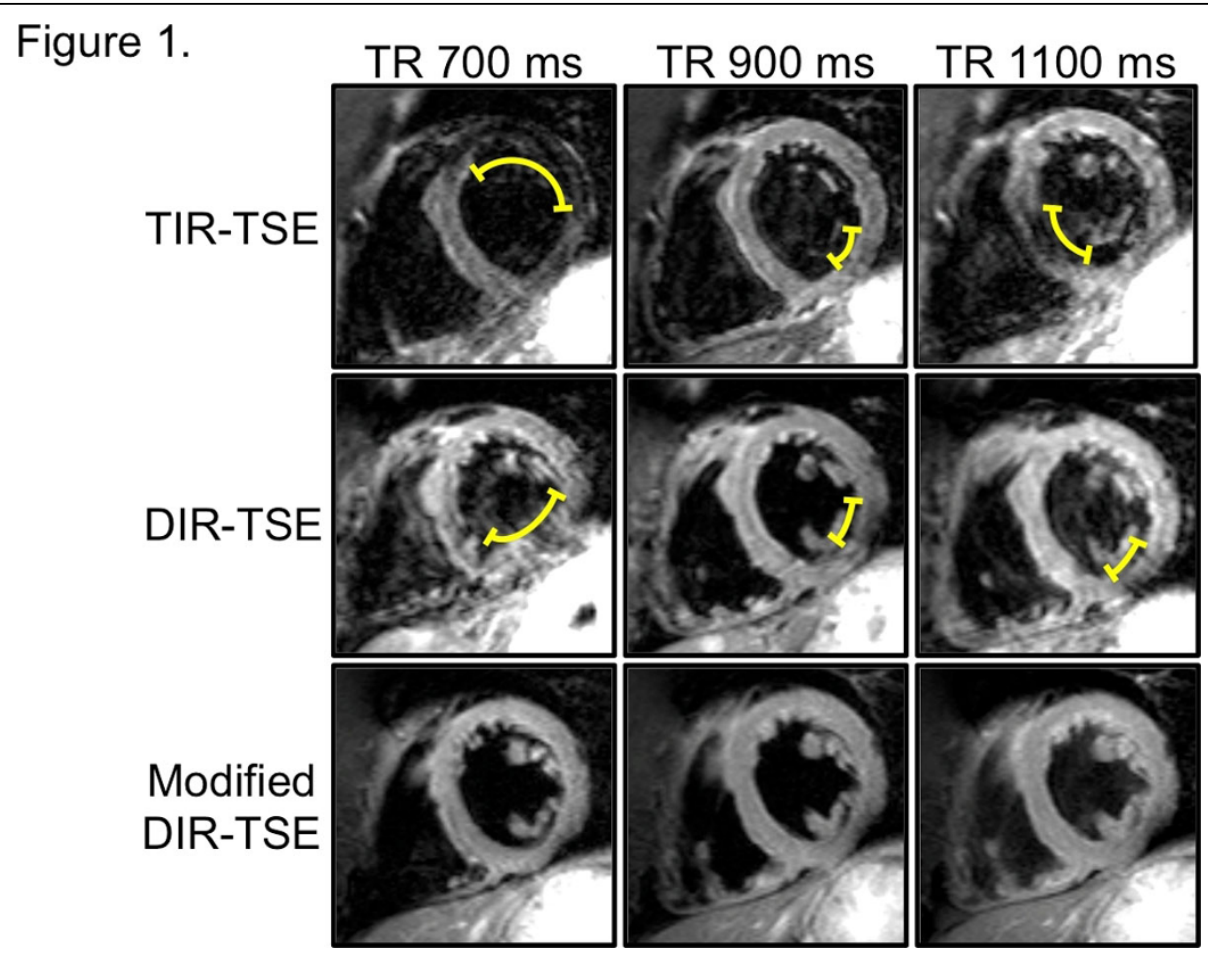

Figure 1

Author details

${ }^{1}$ Cardiology, Duke University, Durham, NC, USA. ${ }^{2}$ Siemens Medical Systems R\&D, Chicago, IL, USA.

Published: 1 February 2012

doi:10.1186/1532-429X-14-S1-0113

Cite this article as: Wince et al:: Assessment and improvement of image homogeneity in black-blood T2-weighted turbo spin-echo CMR. Journal of Cardiovascular Magnetic Resonance 2012 14(Suppl 1):0113.
Submit your next manuscript to BioMed Central and take full advantage of:

- Convenient online submission

- Thorough peer review

- No space constraints or color figure charges

- Immediate publication on acceptance

- Inclusion in PubMed, CAS, Scopus and Google Scholar

- Research which is freely available for redistribution 